\title{
On the Response of Nascent Soot Nanostructure and Oxidative Reactivity to Photoflash Exposure
}

\author{
Wei Wang 1,2, Dong Liu 1,2,*, Yaoyao Ying ${ }^{1,2}$, Guannan Liu ${ }^{1,2}$ and Ye $\mathrm{Wu}^{1,2, *}$ \\ 1 Key Laboratory of Thermal Control of Electronic Equipment, Ministry of Industry and Information \\ Technology, Nanjing University of Science and Technology, Nanjing 210094, China; \\ wangwei931019@163.com (W.W.); yingyy0225@163.com (Y.Y.); liuguannan0925@126.com (G.L.) \\ 2 Advanced Combustion Laboratory, School of Energy and Power Engineering, Nanjing University of Science \\ and Technology, Nanjing 210094, China \\ * Correspondence: dongliu@njust.edu.cn (D.L.); ywu@njust.edu.cn (Y.W.); \\ Tel.: +86-183-6296-2967 (D.L.); Fax: +86-25-8431-4960 (D.L.)
}

Academic Editor: Mejdi Jeguirim

Received: 16 June 2017; Accepted: 3 July 2017; Published: 10 July 2017

\begin{abstract}
Soot particles are a kind of major pollutant from fuel combustion. To enrich the understanding of soot, this work focuses on investigating detailed influences of instantaneous external irradiation (conventional photoflash exposure) on nanostructure as well as oxidation reactivity of nascent soot particles. By detailed soot characterizations flash can reduce the mass of soot and soot nanostructure can be reconstructed substantially without burning. After flash, the degree of soot crystallization increases while the soot reactive rate decreases and the activation energy increases. In addition, nanostructure and oxidative reactivity of soot in air and Ar after flash are different due to their different thermal conductivities.
\end{abstract}

Keywords: photoflash exposure; nascent soot particles; nanostructure; oxidation reactivity

\section{Introduction}

Soot particles are one kind of major pollutant from fuel combustion. Soot emission to the environment reduces air quality, affects the climate and can cause health problems such as asthma, lung cancer, and cardiovascular disease [1,2]. For this reason, soot formation in combustion has been widely investigated in diesel engine [3-5] and different flame structures [6,7] over the years. Therefore, the reduction of soot emission is a great challenge and it is of great importance to understand the soot formation process and characteristics at different operating conditions.

Investigations of soot nanostructure and reactivity can contribute to fully understanding soot formation and characteristics. Soot nanostructure impacts soot oxidation reactivity and has been widely studied [8-11]. Vander Wal et al. [12] investigated the dependence of soot oxidation rate upon the nanostructure including fringe length, curvature and separation distance of the carbon layers. They found that soot with shorter fringe length, higher curvature and larger separation distance had higher oxidation reactivity. Raj et al. [13] investigated the effect of planar and curved PAHs (polycyclic aromatic hydrocarbons) structures comprising primary soot particles on their oxidation reactivity. They found the average activation energy of curved soot (soot with higher fringe curvature) was lower than that of planar soot (soot with tinier fringe curvature), and curved soot showed higher reactivity. Quantum calculations were conducted to confirm the impact of curvature on reducing the activation energy.

Soot formation and characteristics are not only dependent on flame conditions, but also may be highly related to the external environment such as external irradiation. However, the latter aspect has not been well studied until now. In recent years, the studies have found that externally 
introduced irradiation based on the different physical and chemical characteristics has good emission characteristics and high economic performance $[14,15]$. It has been proved that a continuous externally introduced irradiation source can increase the soot loading of the flame, influence soot morphology and the in-flame soot growth processes [16]. The studies above are almost always restricted to continuous irradiation, but influences of instantaneous irradiation on soot materials have rarely been studied and are still not well understood to date.

Since flash ignition of carbon nanotubes using conventional photoflash was first discovered by Ajayan et al. [17], the processing and ignition of nanomaterials using normal photoflash have been attracting increased interests from many researchers [18-21]. That is not only because of its low energy requirement for processing and ignition nanomaterials, but also because of its low cost, distributed light area and easy access etc. The color temperature of photoflash is about $5500 \mathrm{~K}$, intrinsically the same to that of solar light. However, the light from the photoflash can be considered as one kind of instantaneous irradiation, which is different to solar irradiation. Therefore, the photoflash is of great interest because it can provide a useful discussion and give better understanding for controlling the soot properties by introducing external instantaneous radiation.

Moreover, the present work is focused on the response of nascent soot properties to photoflash exposure. Several previous investigations have been confirmed that the flame configuration known as an inverse diffusion flame (IDF) appears to be a good alternative for studying the chemistry of the soot inception process [22-24]. Compared to other types of configurations, the precursor material and young soot particles can be collected from an IDF without oxidation. As a result, the soot generated from an IDF is selected as the samples' exposure to photoflash in the present work.

The aim of the present work is to investigate the effects of conventional photoflash exposures as one kind of instantaneous irradiation on soot nanostructure and oxidative reactivity under different operating conditions. The morphology and structures of soot samples before and after flash are examined by X-ray diffraction (XRD), high-resolution transmission electron microscopy (HRTEM) and helium ion microscopy (HIM). Temperature-programmed oxidation (TPO) experiments are performed in a flow-reactor. The deeper oxidative reactivity and apparent kinetic parameters are evaluated by thermogravimetric analysis (TGA).

\section{Materials and Methods}

\subsection{Sample Preparation}

The nascent soot was collected from the ethylene IDFs. A co-annular laminar IDF burner was setup for the present study. The IDF burner consists of three concentric stainless steel tubes, as shown in Figure 1. The inner diameters of the central tube, the intermediate tube and the outer tube are $3.86 \mathrm{~mm}, 15.30 \mathrm{~mm}$ and $32.36 \mathrm{~mm}$ respectively. In the IDF configuration, the central tube is for the oxidizer stream (air with $99.999 \%$ purity), and the intermediate tube is for the fuel stream (ethylene with $99.95 \%$ purity). Nitrogen, with $99.999 \%$ purity, was ejected from the outer tube as a shield to prevent the formation of secondary flames between the fuel and ambient air. The experimental conditions were summarized in Table 1. The soot particles were collected from $30 \mathrm{~mm}$ from the burner tip using a quartz disk with a diameter of $50 \mathrm{~mm}$. Soot collection time was determined for $30 \mathrm{~min}$. Soot particles were sampled onto the quartz surface, which was kept cold by circulating water. The soot samples were subsequently scraped from the quartz disk and ground into powder by a spatula for several minutes. 


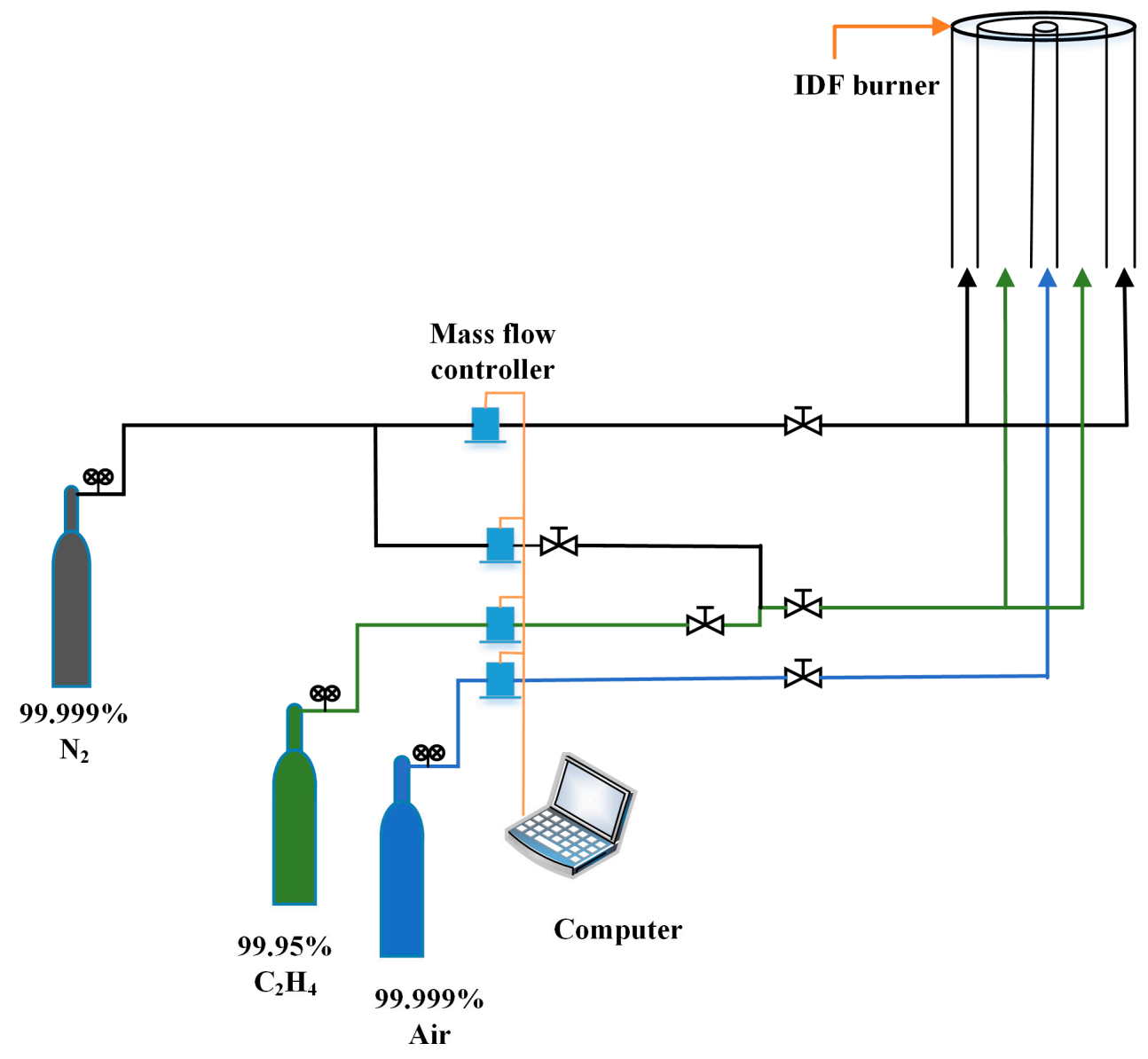

Figure 1. Schematic diagram of IDF experimental system.

Table 1. Experimental conditions in inverse diffusion flame.

\begin{tabular}{ccc}
\hline & Gas & Gas Flow Rate (L/min) \\
\hline & $\mathrm{C}_{2} \mathrm{H}_{4}$ & 0.7 \\
IDF & Air & 0.7 \\
& $\mathrm{~N}_{2}$ (Carrier) & 0.7 \\
& $\mathrm{~N}_{2}$ (Protector) & 13 \\
\hline
\end{tabular}

\subsection{Flash-Exposure}

A camera flash light (Triopo 690N, Triopo, Guangzhou, China) equipped with a xenon lamp (Figure 2) was used for the flash test and the flash duration time is about $7.8 \mathrm{~ms}$. The maximum areal energy density of the photoflash was about $1.97 \mathrm{~J} / \mathrm{cm}^{2}$ per pulse. The emission spectrum (Figure 3) for the conventional xenon photoflash, which was measured by the Ocean Optics USB 2000+ (Ocean Optics, Shanghai, China) equipped with QP400-2-VIS-NIR fiber (Ocean Optics, Shanghai, China). The flashlight mainly consists of visible and infrared light. $5 \mathrm{mg}$ of soot was placed on top of a $1 \mathrm{~mm}$ thick glass slide above the photoflash. Concerning the effects of total flash times and flash environment/atmosphere, 1 time and 20 times flash were carried out in air and argon under the ambient temperature, respectively. Nascent soot with no flash, 1 time flash and 20 times flash in air and argon were denoted as $\mathrm{F} 0, \mathrm{~F}_{\text {air }} 1, \mathrm{~F}_{\mathrm{air}} 20, \mathrm{~F}_{\mathrm{ar}} 1$ and $\mathrm{F}_{\mathrm{ar}} 20$, respectively. 


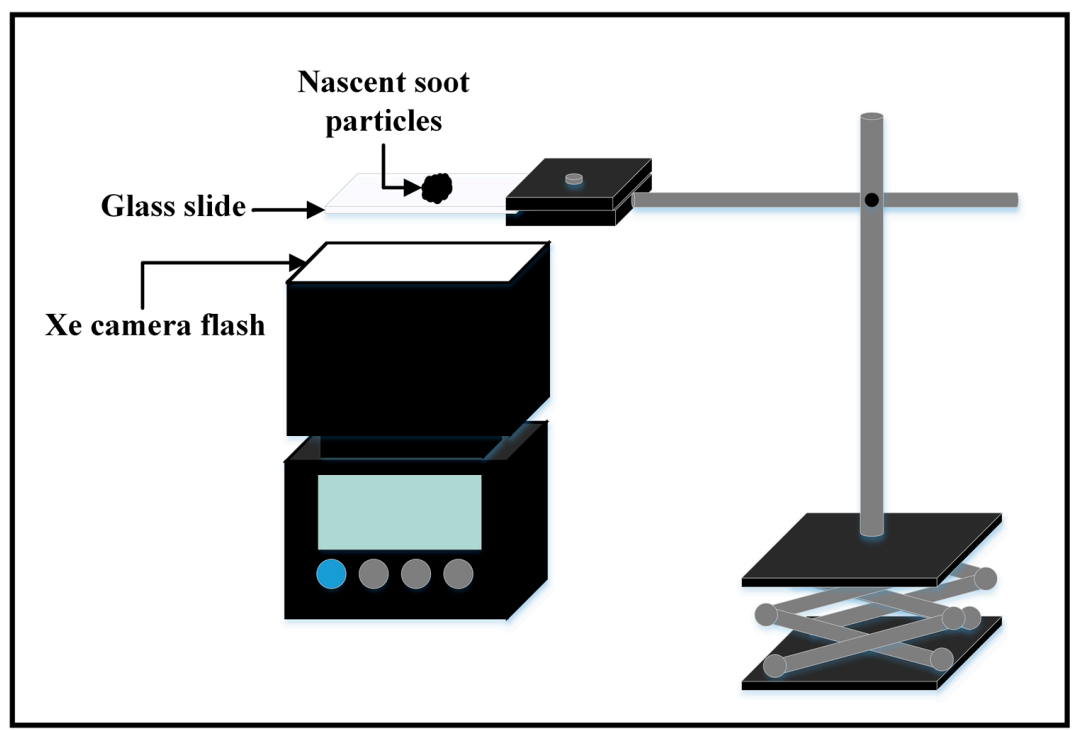

Figure 2. Schematic diagram of flash-exposure experimental setup.

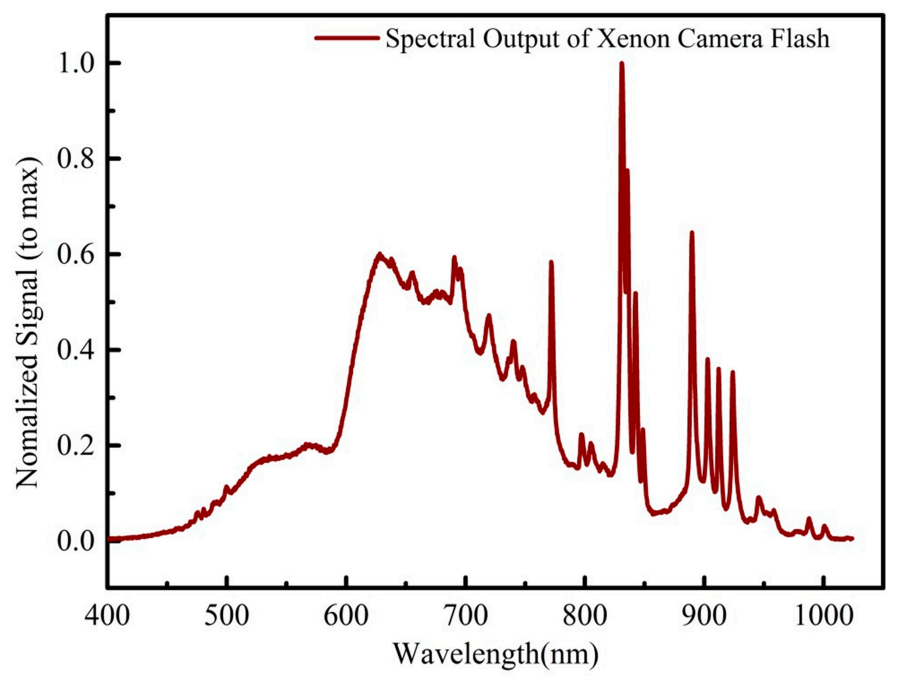

Figure 3. The emission spectrum for the conventional xenon photoflash.

\subsection{Characterization}

The microscopic morphology of the samples was observed using HIM taken on ZEISS ORION (Carl Zeiss AG, Oberkochen, Germany). TEM images were captured with a magnification of $43,000 \times$ and $670,000 \times$ by a FEI Titan G2 60-300 instrument (Field Emission Inc., Hillsboro, OR, USA). The HRTEM image processing was performed by homemade MATLAB analysis algorithms. The method is similar to the ones developed by Yehliu et al. [25,26] and Ying et al. [9,10]. The image processing involves several operations such as negative transformation, region of interest selection, contrast enhancement, Gaussian low pass filter, top-hat transformation, thresholding to obtain a binary image, morphological modification, skeletonization, and short fringes and boundary fringes removal. The fringe length is a measurement of the physical size of the carbon layer planes; tortuosity is a measurement of the degree of curvature for the fringe and is defined as the ratio of the actual fringe length to the straight-line distance; separation is the distance between two adjacent carbon layer planes and is defined as the vertical distance of two mutual parallel carbon crystallites. The flow chart of HRTEM image processing was presented in Figure S1. The largest standard deviation of fringe length, tortuosity and separation is $0.02 \mathrm{~nm}, 0.01$ and $0.02 \mathrm{~nm}$, respectively. 
XRD patterns of the samples were collected using a D8 Advance X-ray diffractometer (Bruker, Karlsruhe, Germany) with $\mathrm{CuK} \alpha$ radiation $(1.5418 \AA, 45 \mathrm{kV}, 25 \mathrm{~mA})$. The scan range of $200-100 \theta$ was used with scan step size of 0.05 and scan speed of $0.2 \mathrm{~s} /$ step.

The TPO experiments were conducted in a flow reactor (BTF-1500C, BEQ, Hefei, China), which consists of a quartz tube $(100 \mathrm{~cm}$ long, $5 \mathrm{~cm}$ inner diameter) housed in a tube furnace. With a total flow rate of $400 \mathrm{~mL} / \mathrm{min}$, the samples were initially heated in $\mathrm{N}_{2}$ from $50{ }^{\circ} \mathrm{C}$ to $200{ }^{\circ} \mathrm{C}$ at a rate of $10{ }^{\circ} \mathrm{C} / \mathrm{min}$ for water removal and then heated in $\mathrm{O}_{2} / \mathrm{N}_{2}\left(50 \% \mathrm{O}_{2}\right)$ stepped by $3{ }^{\circ} \mathrm{C} / \mathrm{min}$ to $500{ }^{\circ} \mathrm{C}$. The effluent gas was connected to a gas chromatograph (GC, Agilent 7890B, Agilent, Santa Clara, CA, USA) for composition analysis.

In order to further understand the soot oxidation reactivity and kinetics, a NETZSCH STA 449 F3 (NETZSCH, Bavarian, Germany) thermogravimetric analyzer was used. Approximate $10 \mathrm{mg}$ of the soot sample was loaded in a quartz crucible and heated under $\mathrm{O}_{2} / \mathrm{Ar}\left(100 \mathrm{~mL} / \mathrm{min}, 22 \% \mathrm{O}_{2}+78 \% \mathrm{Ar}\right)$ from $50{ }^{\circ} \mathrm{C}$ to the desired temperature $\left(480-550{ }^{\circ} \mathrm{C}\right)$ stepped by $20^{\circ} \mathrm{C} / \mathrm{min}$. The final temperatures remained for $40 \mathrm{~min}$ for isothermal oxidation and the corresponding kinetics analysis.

\subsection{The Calculation Processes of TGA Experiments}

The kinetics of soot oxidation is typical gas-solid reaction, which can be studied by the reported kinetics models [27-30]. According to these models, the reaction rate is modeled by

$$
\begin{gathered}
\mathrm{F}(\alpha)=\mathrm{kt} \\
\mathrm{a}=\frac{\mathrm{m}_{0}-\mathrm{m}_{\mathrm{t}}}{\mathrm{m}_{0}}
\end{gathered}
$$

where $\alpha$ is the mass fraction of oxidized soot, $\mathrm{k}$ is the rate constant of soot oxidation $\left(\mathrm{min}^{-1}\right)$, and $\mathrm{t}$ is reaction time $(\mathrm{min}) . \mathrm{F}(\alpha)$ is a function determined by the chosen mechanisms. The $\mathrm{m}_{t}$ and $\mathrm{m}_{0}$ in Equation (2) are mass of the soot oxidized at any time and initially existing in the initial soot.

Seven common forms of $F(\alpha)$ are listed in Table 2. Appropriate forms of $F(\alpha)$ are determined by fitting $\mathrm{F}(\alpha)$-t. On the basis of Equation (1), a form of $\mathrm{F}(\alpha)$ that gives a linear fit is an appropriate model for the $\mathrm{N}$-desorption reaction ( $\mathrm{N}$ refers to the reaction order), where the slope of the line is equal to $\mathrm{k}$. The reaction rate coefficient is related to the activation energy through the Arrhenius form

$$
\operatorname{lnk}=-\frac{E_{a}}{R T}+\ln \mathrm{A}
$$

where, $E_{a}$ is the activation energy, $R$ is the molar gas constant, $T$ is the absolute temperature, and $\mathrm{A}$ is the frequency factor and it refers to the collision probability of particles and is related to the material physical parameters such as the morphology. The activation energy and frequency factor can be determined for a sample by making a linear fit to the relationship between lnk and 1/T.

Table 2. Seven Common Forms of $F(\alpha)^{a}$.

\begin{tabular}{ccc}
\hline Model Type (Based on Mechanism) & Symbol & $\mathbf{F}(\alpha)$ \\
\hline 1D diffusion & $\mathrm{D}_{1}$ & $\alpha^{2}$ \\
2D diffusion & $\mathrm{D}_{2}$ & $\alpha+(1-\alpha) \ln (1-\alpha)$ \\
3D diffusion & $\mathrm{D}_{3}$ & {$[1-(1-\alpha) 1 / 3]^{2}$} \\
Ginstling-Brounshtein & $\mathrm{D}_{4}$ & $1-(2 / 3) \alpha-(1-\alpha)^{2 / 3}$ \\
Prout-Tompkins & $\mathrm{A}_{\mathrm{u}}$ & $\ln (\alpha \mathrm{n}(\alpha-\alpha))$ \\
contracting surface/volume & $\mathrm{R}_{\mathrm{n}}$ & $1-(1-\alpha)^{1 / \mathrm{n}}$ \\
Avrami-Erofeyev & $\mathrm{A}_{\mathrm{m}}$ & {$[-\ln (1-\alpha)]^{1 / \mathrm{m}}$} \\
\hline
\end{tabular}

a The values of $\mathrm{n}$ and $\mathrm{m}$ are reaction orders. 


\section{Results and Discussion}

Upon the flash exposure, some pale yellow smoke, which was considered to be volatile, escaped from soot and the mass of soot $\mathrm{F}_{\text {air }} 20$ reduced about $17 \%$. Compared with F0, morphology, nanostructure and oxidative reactivity of $\mathrm{F}_{\mathrm{air}} 1$ and $\mathrm{F}_{\mathrm{ar}} 1$ have no significant differences (Figures in Supplementary Materials). Moreover, based on the analysis of oxidation, there is no obvious difference among the soot in F0, $\mathrm{F}_{\text {air }} 1$ and $\mathrm{F}_{\mathrm{ar}} 1$. Therefore, the present work is focused on the 20 time flash in air and argon, compared to F0. Figure 4 shows morphologies and nanostructures of F0, $\mathrm{F}_{\text {air }} 20$ and $\mathrm{F}_{\mathrm{ar}} 20$. In numerous previous experimental investigations of flames, the primary particles covered by a film-like deposition with irregular shape were considered as nascent soot particles [9,22-24]. As Figure $4 \mathrm{~d}$ shows the morphology of the soot particles from pure ethylene flames (F0), we can clearly see that particles in F0 show liquid-like materials with irregular shapes, which are partially transparent to the electron beam. As a result, we classify the particles observed in Figure $4 \mathrm{~d}$ as nascent soot particles that are just beginning to carbonize. Figure $4 \mathrm{a}-\mathrm{c}$ show the typical HIM images of F0, $\mathrm{F}_{\text {air }} 20$ and $\mathrm{F}_{\mathrm{ar}} 20$. In all micrographs a large number of soot aggregates can be observed. There are differences in the particle size distribution. Among the average particle size of the three samples, F0 occupies the first place and $\mathrm{F}_{\text {air }} 20$ comes the second. It is also noted that there are many tiny particles (Figure $4 \mathrm{e}, \mathrm{f}$ ) in comparison with Figure 4d in the typical TEM images, which are consistent with HIM analysis. Carbon nanotubes (CNTs) can be ignited by a photoflash in the previous works [31]. Similarly, the emissivity of soot is very high and the soot samples can absorb a large amount of flash light and convert it to heat. The heat cannot be dissipated in such a short flash time and then is confined within the particles, resulting in a rapid temperature increase of soot particles. The temperature causes a large of quantity of volatile material to be released from soot. It also results in larger soot particles broken into several small particles agglomerates [32]. Figure 4g-i show the HRTEM images of three soot samples. Figure 4g, corresponding to F0, shows shorter graphitic layers with no apparent defined orientation in relation to each other. In contrast, corresponding to $\mathrm{F}_{\text {air }} 20$ and $\mathrm{F}_{\mathrm{ar}} 20$, the graphitic layers are large and parallel to each other in Figure 4h,i. Therefore, the changes observed in soot should be mainly due to combinations of heating effects and photo physical processes.

To further analyze carbon morphology characteristics of the samples, lattice fringe analysis on fringe length, tortuosity and separation information derived from the corresponding skeleton images (Figure 4j-1) are summarized in Figure 5. The skeleton images (extracted from the yellow circles marked in Figure 4g-i) show the regions of interest of the primary particles and the layer within these areas as line segments in a binary image. As shown in Figure 5, there are significant differences of the fringe length, tortuosity and separation distance histograms among F0, $\mathrm{F}_{\text {air }} 20$ and $\mathrm{F}_{\mathrm{ar}} 20$. F0 has the lowest mean fringe length; $\mathrm{F}_{\mathrm{air}} 20$ and $\mathrm{F}_{\mathrm{ar}} 20$ have a concentrated distribution of separation between 0.32 and $0.4 \mathrm{~nm}$. From the histograms of tortuosity for these three samples, the breadth of the tortuosity distributions decreases, and the mean shifts toward smaller values, reflecting the less-amorphous structure of $\mathrm{F}_{\mathrm{air}} 20$ and $\mathrm{F}_{\mathrm{ar}} 20$. These results suggest that the nascent soot have higher graphitization degree in $\mathrm{F}_{\text {air }} 20$ and $\mathrm{F}_{\mathrm{ar}} 20$ than in F0.

XRD spectra of the three samples are presented in Figure 6. The diffraction peaks shift to the right and are approaching up the band $0.02(2 \theta \approx 25)$ after flash exposure. It indicates that the degree of graphite in nascent soot has been increased by photoflash. This result proves the analyses above on the nanostructure of nascent soot and shows good agreement with the HRTEM results. The samples after flash in air and Ar atmosphere reveal that soot nanostructure can be reconstructed substantially without burning. In air, the flash makes the sample exhibit longer graphitic layers. Compared with air, the degree of graphitization of soot in Ar is higher. The reason may be that the thermal conductivity of air $\left(0.023 \mathrm{~W} \mathrm{~m}^{-1} \mathrm{~K}^{-1}\right)$ is higher than that of $\operatorname{Ar}\left(0.0177 \mathrm{~W} \mathrm{~m}^{-1} \mathrm{~K}^{-1}\right)$ [17].

As a comparison, oxidation of nascent soot with volatile removal (denoted as F1) is analyzed by the flow-reactor and TGA. The soot sample for F1 is loaded in a quartz tube, heated under $\mathrm{N}_{2}$ $(400 \mathrm{~mL} / \mathrm{min})$ at $320^{\circ} \mathrm{C}$ and the temperature lasts for $60 \mathrm{~min}$. Figure $7 \mathrm{a}-\mathrm{c}$ show TPO in a flow-reactor and isothermal oxidation in TGA for four samples. The mole fraction peak of $\mathrm{CO}$ and $\mathrm{CO}_{2}$ measured 
by GC in TPO experiments follow the order of $\mathrm{F} 0>\mathrm{F}_{\mathrm{air}} 20>\mathrm{F}_{\mathrm{ar}} 20>\mathrm{F} 1$ (in Figure 7a,b). It implies that the carbon conversion of $\mathrm{F} 0$ is larger than the other three samples at the peak value. Also, the mass loss curves of four samples in TGA at $500{ }^{\circ} \mathrm{C}$ show similar a tendency feature in Figure $7 \mathrm{c}$ and it indicates that the oxidation of $\mathrm{F} 0$ is faster than that of $\mathrm{F}_{\mathrm{air}} 20$ and $\mathrm{F}_{\mathrm{ar}} 20$. In the TGA experiments, according to the kinetic analysis, the best appropriate model $F(\alpha)$ is Avrami-Erofeyev model and the reaction order for the model is 1 . Arrhenius plot of intrinsic rate constant for all samples are shown in Figure 7. Also, the apparent kinetic parameters including activation energies and pre-exponential factors are presented in Table 3. According to the kinetics analysis, the resulting activation energy for oxidation of the soot samples ranges from 99.39 to $108.1 \mathrm{~kJ} / \mathrm{mol}$ and shows a ranking of $\mathrm{F} 0<\mathrm{F}_{\mathrm{air}} 20<\mathrm{F}_{\mathrm{ar}} 20$. As mentioned before, the longer the graphitic layer, the lower their reactivity, which confirms the oxidative reactivity of nascent soot has been reduced by the photoflash exposure.

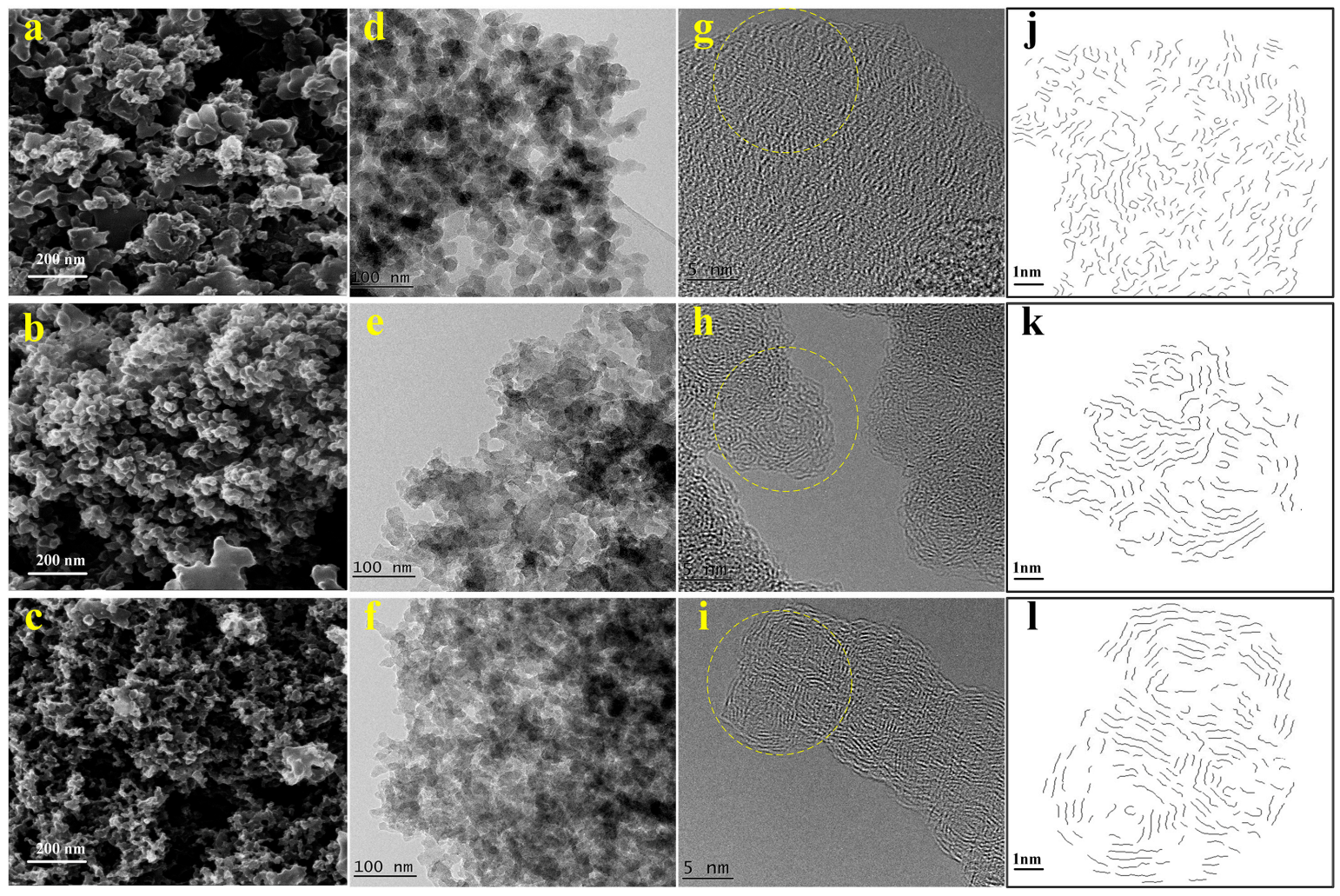

Figure 4. HIM images, typical TEM images and HRTEM images of F0, $\mathrm{F}_{\text {air }} 20$ and $\mathrm{F}_{\mathrm{ar}} 20$. (a) HIM image of F0; (b) HIM image of $\mathrm{F}_{\text {air }} 20$; (c) HIM image of $\mathrm{F}_{\mathrm{ar}} 20$; (d) typical TEM image of F0; (e) typical TEM image of $\mathrm{F}_{\mathrm{air}} 20$; (f) typical TEM image of $\mathrm{F}_{\mathrm{ar}} 20$; (g) HRTEM image of F0; (h) HRTEM image of $\mathrm{F}_{\text {air }}$ 20; (i) HRTEM image of $\mathrm{F}_{\mathrm{ar}} 20$; (j) the skeleton image of $\mathrm{F} 0$; (k) the skeleton image of $\mathrm{F}_{\text {air }} 20$; (1) the skeleton image of $\mathrm{F}_{\mathrm{ar}} 20$. 

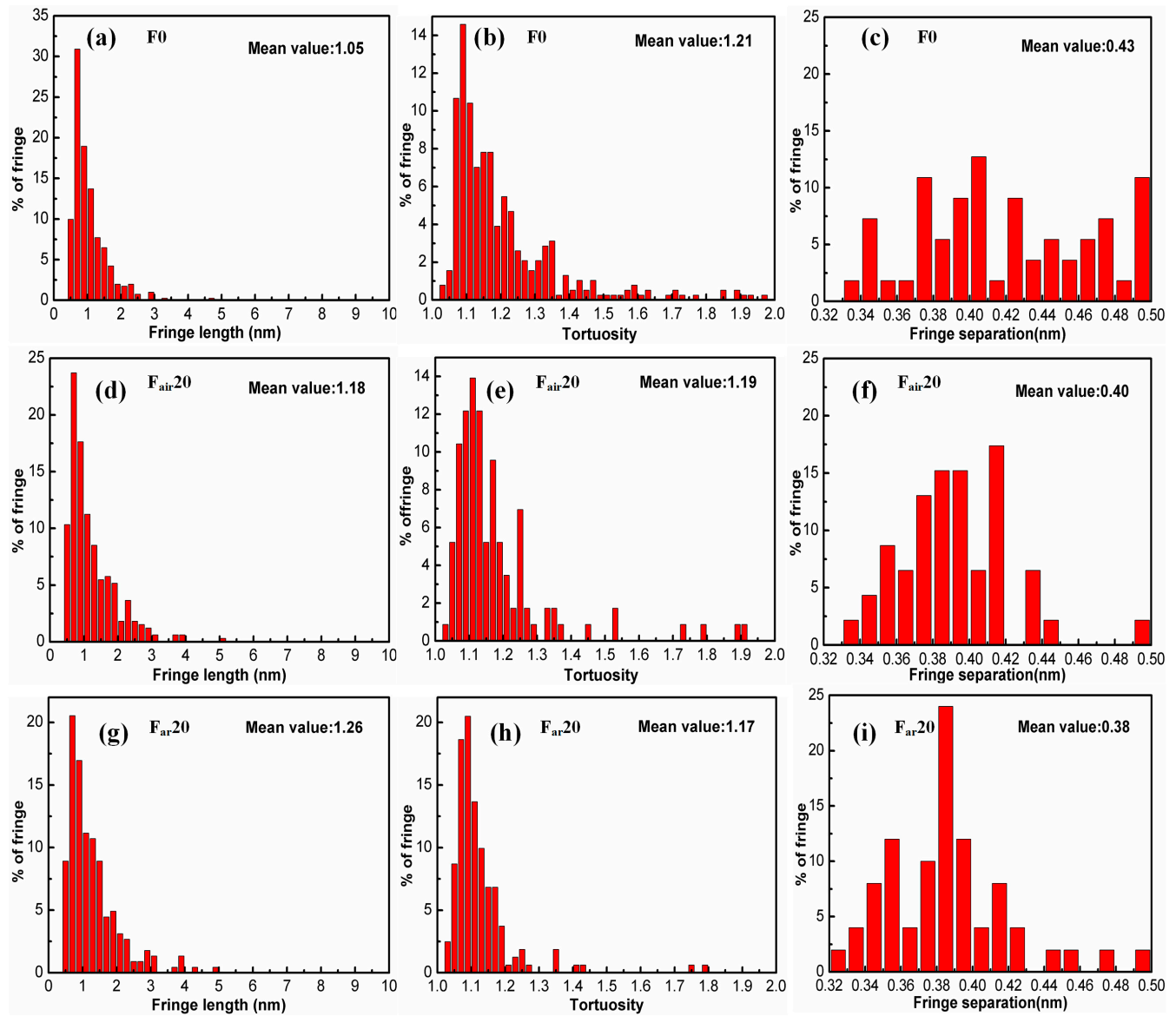

Figure 5. Histograms of fringe length, tortuosity and separation for F0, $\mathrm{F}_{\mathrm{air}} 20$ and $\mathrm{F}_{\mathrm{ar}} 20$ derived from the corresponding skeleton images: (a) Histograms of fringe length for F0; (b) Histograms of tortuosity for F0; (c) Histograms of separation for F0; (d) Histograms of fringe length for Fair20; (e) Histograms of tortuosity for Fair20; (f) Histograms of separation for Fair20; (g) Histograms of fringe length for Far20; (h) Histograms of tortuosity for Far20; (i) Histograms of separation for Far20.

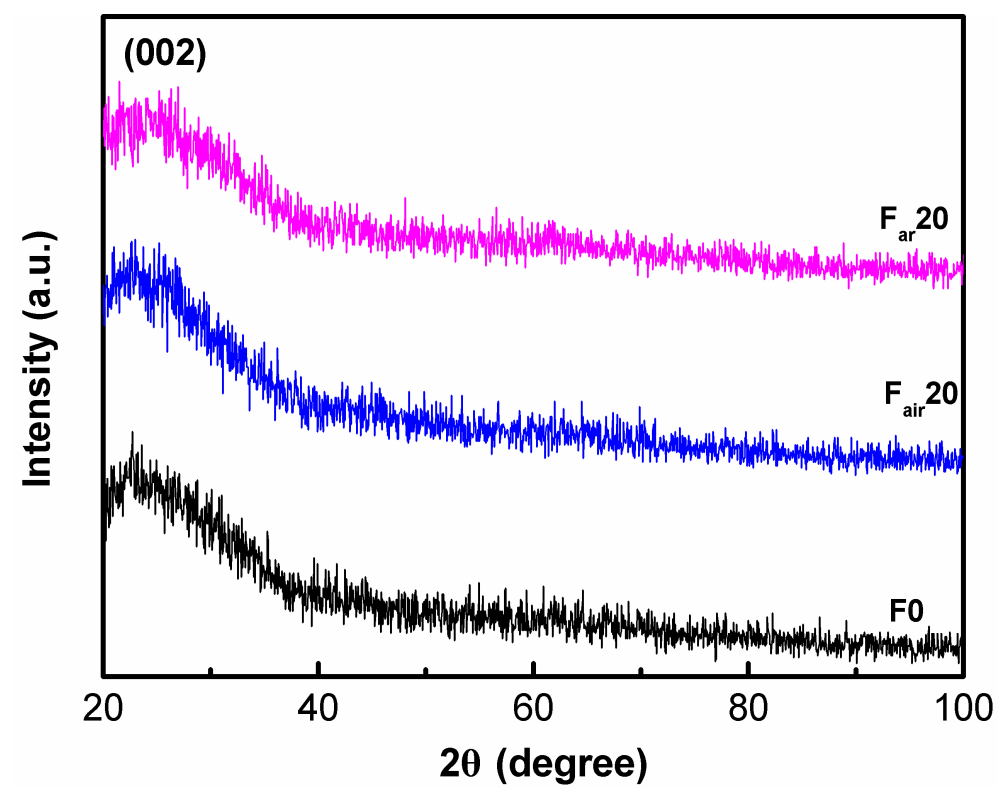

Figure 6. $\mathrm{XRD}$ spectra of $\mathrm{F} 0, \mathrm{~F}_{\mathrm{air}} 20$ and $\mathrm{F}_{\mathrm{ar}} 20$. 

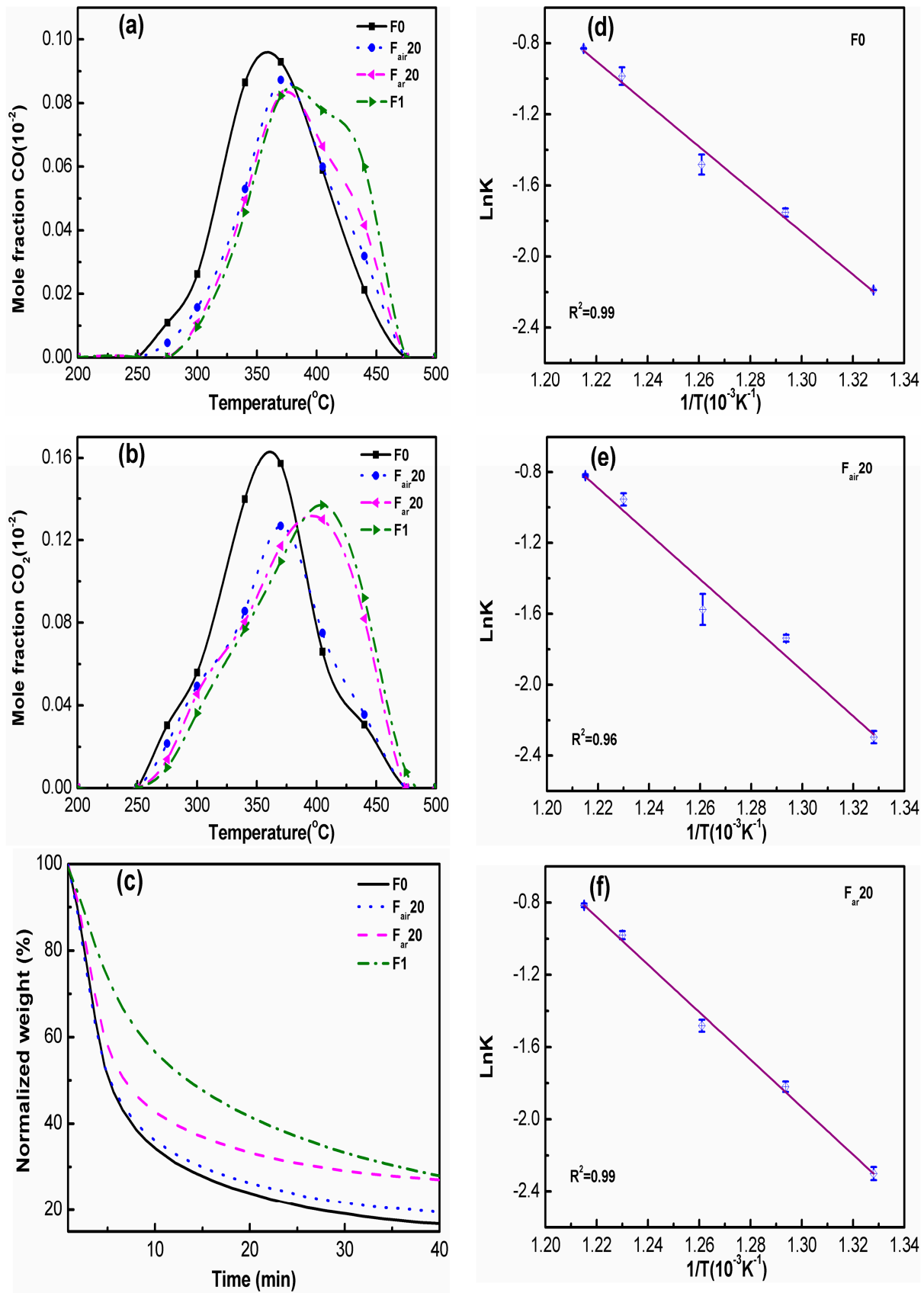

Figure 7. Oxidative behaviors and Arrhenius plot of intrinsic rate constant for samples. (a) CO mole fraction of four samples in TPO experiments; (b) $\mathrm{CO}_{2}$ mole fraction of four samples in TPO experiments; (c) TGA results of isothermal oxidation for four samples at $500{ }^{\circ} \mathrm{C}$; (d) Arrhenius plot of intrinsic rate constant for F0; (e) Arrhenius plot of intrinsic rate constant for $\mathrm{F}_{\text {air }} 20$; (f) Arrhenius plot of intrinsic rate constant for $\mathrm{F}_{\mathrm{ar}} 20$.

Table 3. Apparent kinetic parameters from Arrhenius plot from isothermal oxidation in TGA under different temperatures.

\begin{tabular}{cccc}
\hline Sample & $\mathbf{E}_{\mathbf{a}} \mathbf{( k J / m o l )}$ & $\mathbf{A}\left(\mathbf{m i n}^{-\mathbf{1}}\right)$ & $\boldsymbol{R}^{\mathbf{2}}$ \\
\hline $\mathrm{F} 0$ & $99.39 \pm 1.86$ & $8.7 \times 10^{5}$ & 0.99 \\
$\mathrm{~F}_{\mathrm{air}} 20$ & $106.79 \pm 2.14$ & $2.6 \times 10^{6}$ & 0.96 \\
$\mathrm{~F}_{\mathrm{ar}} 20$ & $108.10 \pm 1.25$ & $3.2 \times 10^{6}$ & 0.99 \\
\hline
\end{tabular}




\section{Conclusions}

In summary, we have investigated the role of photoflash exposure on nascent soot nanostructure and oxidative reactivity. The findings suggest that photoflash exposure can reduce the mass of nascent soot. Soot nanostructure can be reconstructed substantially without burning. After flash, the degree of soot crystallization increases while the soot reactive rate decreases and the activation energy increases. Moreover, nanostructure and oxidative reactivity of $\mathrm{F}_{\mathrm{air}} 20$ and $\mathrm{F}_{\mathrm{ar}} 20$ are different due to their different thermal conductivities.

Supplementary Materials: The following are available online at www.mdpi.com/1996-1073/10/7/961/s1, Figure S1: Flow chart of HRTEM image processing. Figure S2: HIM images, typical TEM images and HRTEM images of $F_{a i r} 1$ and $F_{a r} 1$. (a) HIM image of $F_{a i r} 1$; (b) typical TEM image of $F_{a i r} 1$; (c) HRTEM image of $F_{a i r} 1$; (d) HIM image of $\mathrm{F}_{\mathrm{ar}} 1$; (e) typical TEM image of $\mathrm{F}_{\mathrm{ar}} 1$; (f) HRTEM image of $\mathrm{F}_{\mathrm{ar}} 1$. Figure S3: Histograms of fringe length, tortuosity and separation for $\mathrm{F}_{\mathrm{air}} 1$ and $\mathrm{F}_{\mathrm{ar}} 1$. Figure S4: Oxidative behaviors for the three samples. (a) CO mole fraction of three samples in TPO experiments; (b) $\mathrm{CO}_{2}$ mole fraction of three samples in TPO experiments; (c) TGA results of isothermal oxidation for three samples at $500{ }^{\circ} \mathrm{C}$.

Acknowledgments: This work was supported by the National Natural Science Foundation of China (51576100, 51506095), the Jiangsu Provincial Natural Science Foundation of China (BK20140034), the Jiangsu Provincial Innovative Project of Graduate Education (KYZZ16_0184) and the Jiangsu Provincial Project of "Six Talent Summit" (2014-XNY-002, 2015-XNY-004). HRTEM experiment was performed at Materials Characterization Facility of Nanjing University of Science and Technology by Jizi Liu.

Author Contributions: Wei Wang performed the experiments, analyzed the data and wrote the paper; Dong Liu supervised this project, designed the experiments, analyzed the data and revised the paper; Yaoyao Ying and Guannan Liu helped the experiments and analyzed the data; Ye Wu revised the paper and discussed.

Conflicts of Interest: The authors declare no conflict of interest.

\section{References}

1. Ramanathan, V.; Carmichael, G. Global and regional climate changes due to black carbon. Nat. Geosci. 2008, 1, 221-227. [CrossRef]

2. Chameides, W.L.; Bergin, M. Soot takes center stage. Science 2002, 297, 2214-2215. [CrossRef] [PubMed]

3. Mattarelli, E.; Rinaldini, C.A.; Savioli, T. Combustion Analysis of a Diesel Engine Running on Different Biodiesel Blends. Energies 2015, 8, 3047-3057. [CrossRef]

4. Giakoumis, E.G.; Zachiotis, A.T. Investigation of a Diesel-Engined Vehicle's Performance and Emissions during the WLTC Driving Cycle-Comparison with the NEDC. Energies 2017, 10, 240. [CrossRef]

5. Yoon, S.H.; Han, S.C.; Lee, C.S. Effects of High EGR Rate on Dimethyl Ether (DME) Combustion and Pollutant Emission Characteristics in a Direct Injection Diesel Engine. Energies 2013, 6, 5157-5167. [CrossRef]

6. Yan, W.; Chen, D.; Yang, Z.; Yan, E.; Zhao, P. Measurement of Soot Volume Fraction and Temperature for Oxygen-Enriched Ethylene Combustion Based on Flame Image Processing. Energies 2017, 10, 750. [CrossRef]

7. De Falco, G.; Moggia, G.; Sirignano, M.; Commodo, M.; Minutolo, P.; D'Anna, A. Exploring Soot Particle Concentration and Emissivity by Transient Thermocouples Measurements in Laminar Partially Premixed Coflow Flames. Energies 2017, 10, 232. [CrossRef]

8. Seong, H.J.; Boehman, A.L. Studies of soot oxidative reactivity using a diffusion flame burner. Combust. Flame 2012, 159, 1864-1875. [CrossRef]

9. Ying, Y.; Xu, C.; Liu, D.; Jiang, B.; Wang, P.; Wang, W. Nanostructure and Oxidation Reactivity of Nascent Soot Particles in Ethylene/Pentanol Flames. Energies 2017, 10, 122. [CrossRef]

10. Ying, Y.; Liu, D. Effects of butanol isomers additions on soot nanostructure and reactivity in normal and inverse ethylene diffusion flames. Fuel 2017, 205, 109-129. [CrossRef]

11. Vander Wal, R.L.; Yezerets, A.; Currier, N.W.; Kim, D.H.; Wang, C.M. HRTEM Study of diesel soot collected from diesel particulate filters. Carbon 2007, 45, 70-77. [CrossRef]

12. Vander Wal, R.L.; Tomasek, A.J. Soot Nanostructure: Definition, Quantification and Implications. SAE Trans. 2005, 114, 429-436.

13. Raj, A.; Yang, S.Y.; Cha, D.; Tayouo, R.; Chung, S.H. Structural effects on the oxidation of soot particles by O2: Experimental and theoretical study. Combust. Flame 2013, 160, 1812-1826. [CrossRef] 
14. Choi, M.; Altman, I.S.; Kim, Y.J.; Pikhista, P.V.; Lee, S.T.; Jeong, G.S.; Yoo, J.B. Formation of Shell-Shaped CNPs Above a Critical Laser Power in Irradiated Acetylene. Adv. Mater. 2004, 16, 1721-1725. [CrossRef]

15. Medwell, P.R.; Nathan, G.J.; Chan, Q.N.; Alwahabi, Z.T.; Dally, B.B. The influence on the soot distribution within a laminar flame of radiation at fluxes of relevance to concentrated solar radiation. Combust. Flame 2011, 158, 1814-1821. [CrossRef]

16. Wang, C.; Chan, Q.N.; Kook, S.; Hawkes, E.R.; Lee, J.; Medwell, P.R. External irradiation effect on the growth and evolution of in-flame soot species. Carbon 2016, 102, 161-171. [CrossRef]

17. Ajayan, P.M.; Terrones, M.; de la Guardia, A.; Huc, V.; Grobert, N.; Wei, B.Q.; Lezec, H.; Ramanath, G.; Ebbesen, T.W. Nanotubes in a flash-ignition and reconstruction. Science 2002, 296, 705. [CrossRef] [PubMed]

18. Kim, J.H.; Kim, S.B.; Choi, M.G.; Kim, D.H.; Kim, K.T.; Lee, H.M.; Lee, H.W.; Kim, J.M.; Kim, S.H. Flash-ignitable nanoenergetic materials with tunable underwater explosion reactivity: The role of sea urchin-like carbon nanotubes. Combust. Flame 2015, 162, 1448-1454. [CrossRef]

19. Ohkura, Y.; Rao, P.M.; Zheng, X. Flash ignition of Al nanoparticles: Mechanism and applications. Combust. Flame 2011, 158, 2544-2548. [CrossRef]

20. Cote, L.J.; Cruzsilva, R.; Huang, J. Flash Reduction and Patterning of Graphite Oxide and Its Polymer Composite. J. Am. Chem. Soc. 2009, 131, 11027-11032. [CrossRef] [PubMed]

21. Xiang, X.; Xiang, S.-B.; Wang, Z.; Wang, X.; Hua, G. Photo-responsive behaviors and structural evolution of carbon-nanotube-supported energetic materials under a photoflash. Mater. Lett. 2012, 88, 27-29. [CrossRef]

22. Velásquez, M.; Mondragón, F.; Santamaría, A. Chemical characterization of soot precursors and soot particles produced in hexane and diesel surrogated using an inverse diffusion flame burner. Fuel 2013, 104, 684-690. [CrossRef]

23. Blevins, L.G.; Fletcher, R.A.; Benner, B.A., Jr.; Steel, E.B.; Mulholland, G.W. The existence of young soot in the exhaust of inverse diffusion flames. Proc. Combust. Inst. 2002, 29, 2325-2333. [CrossRef]

24. Santamaría, A.; Yang, N.; Eddings, E.; Mondragón, F. Chemical and morphological characterization of soot and soot precursors generated in an inverse diffusion flame with aromatic and aliphatic fuels. Combust. Flame 2010, 157, 33-42. [CrossRef]

25. Yehliu, K.; Vander Wal, R.L.; Boehman, A.L. Development of an HRTEM image analysis method to quantify carbon nanostructure. Combust. Flame 2011, 158, 1837-1851. [CrossRef]

26. Yehliu, K.; Vander Wal, R.L.; Boehman, A.L. A comparison of soot nanostructure obtained using two high resolution transmission electron microscopy image analysis algorithms. Carbon 2011, 49, 4256-4268. [CrossRef]

27. Mendiara, T.; Alzueta, M.U.; Millera, A.; Bilbao, R. Oxidation of Acetylene Soot Influence of Oxygen Concentration. Energ. Fuel 2007, 21, 3208-3215. [CrossRef]

28. Mendiara, T.; Alzueta, M.U.; Millera, A.; Bilbao, R. Acetylene soot reaction with NO in the presence of CO. J. Hazard. Mater. 2009, 166, 1389-1394. [CrossRef] [PubMed]

29. Dutcher, B.; Fan, M.; Leonard, B.; Dyar, M.D.; Tang, J.; Speicher, E.A.; Liu, P.; Zhang, Y. Use of Nanoporous $\mathrm{FeOOH}$ as a Catalytic Support for $\mathrm{NaHCO}_{3}$ Decomposition Aimed at Reduction of Energy Requirement of $\mathrm{Na}_{2} \mathrm{CO}_{3} / \mathrm{NaHCO}_{3}$ Based $\mathrm{CO}_{2}$ Separation Technology. J. Phys. Chem. C 2011, 115, 15532-15544. [CrossRef]

30. Zouaoui, N.; Labaki, M.; Jeguirim, M. Diesel soot oxidation by nitrogen dioxide, oxygen and water under engine exhaust conditions: Kinetics data related to the reaction mechanism". C. R. Chim. 2014, 17, 672-680. [CrossRef]

31. Tseng, S.H.; Tai, N.H. Variations in the microstructure and electrical resistance of the SWCNT films under consecutive photoflash exposures. Carbon 2010, 48, 1652-1661. [CrossRef]

32. Inagaki, M.; Kang, F. Materials Science and Engineering of Carbon: Fundamentals, 2nd ed.; Tsinghua University Press: Beijing, China, 2014; pp. 219-525.

(C) 2017 by the authors. Licensee MDPI, Basel, Switzerland. This article is an open access article distributed under the terms and conditions of the Creative Commons Attribution (CC BY) license (http://creativecommons.org/licenses/by/4.0/). 